\title{
HLA-G 14 bp insertion/deletion polymorphism is not associated to proviral load levels and presence of HAM/TSP in Peruvian HTLV-1 infected individuals
}

\author{
Sandra Morales ${ }^{1 *}$, Jason Rosado ${ }^{1}$, Giovanni López $1^{1}$, Jeroen Huyghe ${ }^{2}$, Kristien Verdonck ${ }^{1,3}$, Elsa González ${ }^{1}$ \\ Martin Tipismana', Daniel Clark,4, Guido Vanham, ${ }^{3,5}$, Eduardo Gotuzzo', Guy Van Camp², Lut Van laer², \\ Michael Talledo ${ }^{1,2}$
}

From 15th International Conference on Human Retroviruses: HTLV and Related Viruses Leuven and Gembloux, Belgium. 5-8 June 2011

\section{Introduction}

High HTLV-1 proviral load (PVL) has been associated with HAM/TSP disease in HTLV-1-infected individuals. Human leukocyte antigen (HLA) complex plays an important role in the immune response against virus-infected cells. One mechanism involves HLA-G binding to KIR2DL4 and modulates the activities of Natural Killer and CD8+ T cells. The 14-bp insertion/ deletion in the 3'UTR exon 8 of HLA-G affects the HLA-G-mRNA-stability and therefore the HLA-G-protein levels. We analyzed the distribution of the 14-bp ins/del polymorphism among HTLV-1-infected individuals to evaluate its effect both on PVL and HAM/ TSP.

\section{Subjects and methods}

394 unrelated HTLV-1-infected Peruvian individuals were included in this analysis (254 asymptomatic carriers $[\mathrm{AC}]$ and, $140 \mathrm{HAM} / \mathrm{TSP})$. HLA-G 14-bp ins/del and KIR2DL4 were genotyped with PCR specific primers. PVL was determined by real-time quantitative PCR using human the endogenous retrovirus 3 as reference gene. Associations of KIR-HLA-G ins/del with PVL or HAM/TSP were evaluated through multivariate logistic and linear regression analysis using R-software.

\footnotetext{
* Correspondence: smr_sandra@yahoo.es

${ }^{1}$ Inst de Med Trop Alexander von Humboldt, Univ. Peruana Cayetano Heredia, Lima, Peru

Full list of author information is available at the end of the article
}

\section{Results and conclusions}

KIR2DL4 was observed in all the individuals evaluated. The predominant genotype was $+14-\mathrm{bp} /-14$-bp, both in AC $(50.8 \%)$ and HAM/TSP (50.7\%, P>0.05). HLA-G 14bp ins/del showed no effect on PVL $(P>0.05)$, nor with the presence of HAM/TSP in comparison to AC $(\mathrm{P}>0.05)$. This finding does not agree with the trend of high PVL observed for the -14-bp/-14-bp genotype, compared to +14-bp/-14-bp, +14-bp/+14-bp genotypes, in a Brazilian population. Our results stress the importance of replication studies in independent populations to demonstrate the association of host genetic factors with PVL or disease outcome in HTLV-I-infected subjects.

\section{Author details \\ 'Inst de Med Trop Alexander von Humboldt, Univ. Peruana Cayetano Heredia, Lima, Peru. ${ }^{2}$ Dept of Med Genetics, Univ. of Antwerp, Antwerp, Belgium. ${ }^{3}$ Virology Unit, Dept. of Microbiol., Inst. of Tropical Med., Antwerp, Belgium. ${ }^{4}$ Fac de Ciencias y Filosofía Lab de Inves y Des, Univ. Peruana Cayetano Heredia, Lima, Peru. ${ }^{5}$ Dept of Biomedical Sci., Univ. of Antwerp, Antwerp, Belgium.}

Published: 6 June 2011

\section{doi:10.1186/1742-4690-8-S1-A122}

Cite this article as: Morales et al: HLA-G 14 bp insertion/deletion polymorphism is not associated to proviral load levels and presence of HAM/TSP in Peruvian HTLV-1 infected individuals. Retrovirology 20118 (Suppl 1):A122.

(c) 2011 Morales et al; licensee BioMed Central Ltd. This is an open access article distributed under the terms of the Creative Commons Attribution License (http://creativecommons.org/licenses/by/2.0), which permits unrestricted use, distribution, and reproduction in any medium, provided the original work is properly cited. 